\title{
Alterações da função hepática de camundongos desnutridos e infectados pelo Schistosoma mansoni
}

\author{
Liver function abnormalities in undernourished \\ and Schistosoma mansoni-infected mice
}

\author{
Janira Lúcia Assumpção Couto ${ }^{1}$, Regina Coeli da Silva Vieira ${ }^{2}$, Janine Maciel Barbosa ${ }^{2}$, \\ Sônia Salgueiro Machado ${ }^{3}$ e Haroldo da Silva Ferreira ${ }^{2}$
}

\begin{abstract}
RESUMO
Existem poucos estudos sobre as alterações da função hepática em camundongos com esquistossomose associada à desnutrição. Neste trabalho, os animais foram divididos em quatro grupos, de acordo com as dietas (normal ou hipoprotéica) e infectados ou não pelo Schistosoma mansoni. Todos os grupos desenvolveram-se menos que o grupo controle $(\mathrm{p}<0,0001)$. A mortalidade nos animais foi devida à infecção. Níveis altos de aminotransferases nos animais nutridos e infectados sugerem um processo inflamatório intenso $(\mathrm{p}<0,0001)$. Todos os grupos apresentaram elevação da fosfatase alcalina. Houve aumento da aspartato transferase e da fosfatase alcalina em animais nutridos infectados. As dietas modificaram os níveis de albumina ( $>0,001)$, e das proteínas séricas. Os grupos, comparados ao controle, mostraram baixos níveis de glicose $(p<0,001)$. Este estudo verificou que ambas, infecção e/ou desnutrição, interferiram nos níveis dos indicadores bioquímicos, mas as alterações mais importantes da função hepática ocorreram durante a inflamação intensa causada pela esquistossomose.
\end{abstract}

Palavras-chaves: Esquistossomose. Desnutrição. Função hepática. Camundongos.

\begin{abstract}
There are few studies on liver function abnormalities in mice with schistosomiasis associated with malnutrition. In this study, animals were divided into four groups, according to their diet (normal or low protein) and whether they were infected with Schistosoma mansoni or not. All the groups grew slower than the control did $(\mathrm{p}<0.0001)$. Mortality among the animals occurred because of the infection. High levels of aminotransferases in well-fed animals with infection suggested that there was an intensive inflammatory process $(\mathrm{p}<0.0001)$. All the groups presented high levels of alkaline phosphatase. There were increases in aspartate transferase and alkaline phosphatase in infected well-fed animals. The diets modified the albumin levels $(\mathrm{p}>0.001)$ and the serum proteins. Compared with the controls, the groups showed low levels of glucose $(\mathrm{p}<0.001)$. This study found that both infection and malnutrition interfered with the biochemical indicator levels, but the most important liver function abnormalities occurred during the intense inflammation caused by schistosomiasis.
\end{abstract}

Key-words: Schistosomiasis. Malnutrition. Hepatic function. Mice.

Há cerca de 6,3 milhões de portadores de esquistossomose no Brasil ${ }^{16}$. A evolução da doença e suas manifestações clínicas são influenciadas por fatores tais como a carga parasitária e a condição nutricional do indivíduo ${ }^{7}$. A esquistossomose está quase sempre associada à desnutrição, porque incide com freqüiência na parcela populacional menos favorecida economicamente.

Na desnutrição, a deterioração fisiológica está em consonância com seu grau ${ }^{13} \mathrm{e}$ o fígado, órgão central no metabolismo, tornase quase sempre afetado. Foi observado que a deficiência energético-protéica afeta os sistemas, de modo que, concomitante ao progresso da doença, sobrevém a deterioração das funções hepáticas, com aumento de aminotransferases no soro ${ }^{14}$.

Na esquistossomose mansônica (EM), as alterações hepáticas são as manifestações mais importantes ${ }^{3}$ e estão relacionadas ao estágio da fibrose ${ }^{20}$. Estudos têm mostrado que os testes de função hepática se modificam apenas nas formas mais graves da doença, com organomegalias e ascite $^{1}$ ou ainda, na associação com hepatites ou cirrose descompensada ${ }^{1011}$.

São poucos os estudos sobre alterações funcionais do fígado na esquistossomose associada à desnutrição, daí sua investigação neste

\footnotetext{
1. Setor de Parasitologia, Instituto de Ciências Biológicas e da Saúde, Universidade Federal de Alagoas, Maceió, AL. 2. Faculdade de Nutrição, Universidade Federal de Alagoas, Maceió, AL. 3. Instituto de Química e Biotecnologia, Universidade Federal de Alagoas, Maceió, AL.

Apoio financeiro Fundação de Amparo à Pesquisa do Estado de Alagoas (FAPEAL).

Endereço para correspondência: Dra. Janira Lúcia Assumpção Couto. Rua Desportista Humberto Guimarães 191/102, Ponta Verde, 57035-030 Maceió, AL.

Tel: 5582 3231-2005

e-mail: janelu4@uol.com.br

Recebido para publicação em 17/09/2007

Aceito em 05/08/2008
} 
experimento. 0 objetivo deste trabalho foi investigar possiveis alterações nos indicadores da função hepática de camundongos submetidos simultaneamente à desnutrição e à esquistossomose. Além das enzimas relacionadas àfunção hepática, também foram determinadas a glicemia, a albuminemia e a proteinemia. Foram utilizados camundongos infectados ou não pelo Schistosoma mansoni, aos quais se ministrou uma dieta controle, atendendo a todos os requisitos nutricionais da espécie, ou uma dieta multideficiente, que induz a um estado de desnutrição calórico-protéica, semelhante ao observado nas áreas endêmicas de esquistossomose e pobreza do Nordeste Brasileiro.

\section{MATERIAL E MÉTODOS}

Foram utilizados 75 camundongos albinos suíços machos com 21 dias de idade, dos quais 29 foram mantidos sem infecção e 46 foram infectados através de exposição percutânea, com 40 cercárias de Schistosoma mansoni, aproximadamente. Animais infectados apresentam alta taxa de mortalidade, por isso seu número foi maior no experimento.

Parte dos animais em cada condição foi distribuída conforme o tipo de dieta. A dieta controle foi a ração Labina ${ }^{\circledR}$ (Purina Agribrands do Brasil Ltda), com aproximadamente 23\% de proteína à base de farinha de peixe. Para indução da desnutrição, utilizou-se a Dieta Básica Regional ${ }^{8}$, multideficiente, que se compõe de (g\%): 3,74g de charque, 18,34g de feijão mulatinho (Phaseolus vulgaris), 12,76g de batata doce (Ipomoea batatas) e 58,16g de farinha de mandioca (Manihot utilissima). Ambas as dietas foram ministradas em forma de pellets.

O experimento foi estabelecido com quatro grupos de animais, segundo a infecção ou não e de acordo com o tipo de dieta. Os animais permaneceram durante 13 semanas em gaiolas individuais sob condições padronizadas de iluminação (ciclo de claro/escuro de $12 \mathrm{~h} / 12 \mathrm{~h})$ e temperatura $\left(23^{\circ} \mathrm{C}\right)$.

A presença da infecção e sua intensidade foi averiguada por meio da quantificação do número de ovos eliminados. Para isso, a coleta das fezes dos animais infectados foi efetuada durante a $8^{\text {a }}$ semana do experimento (período pós-postural), para efetuação de exame parasitológico, segundo o método de Kato-Katz $\mathrm{z}^{15}$.

A taxa de mortalidade dos animais no transcorrer do experimento foi registrada, conforme a infecção e condição nutricional.
Para obtenção da curva ponderal, os animais foram pesados a cada sete dias, desde 0 início até o final do experimento, na $13^{\mathrm{a}}$ semana. Nessa etapa final, os animais foram anestesiados em câmara de vaporização de éter, após jejum de 12 horas. A seguir foi efetuada a coleta do sangue através de um tubo capilar que, introduzido na câmara anterior do olho, atingiu o plexo orbital. O soro obtido foi mantido em freezer a $-20^{\circ} \mathrm{C}$ para as análises em laboratório.

A função hepática foi avaliada por meio das dosagens bioquímicas do soro, efetuadas em aparelho de precisão TARGA (Technology Advanced Random Generation Analysis). Foram determinadas as enzimas aspartato transferase (AST), alanina transferase (ALT) e fosfatase alcalina (FA). Também foram verificadas a glicemia, as proteínas totais e a albuminemia.

$\mathrm{Na}$ avaliação dos resultados obtidos nas determinações bioquímicas procedidas no soro dos animais, adotou-se como valores de referência os resultados encontrados no grupo controle e estes em relação aos dados divulgados pelo Centro de Bioterismo da Faculdade de Medicina, Universidade de São Paulo ${ }^{21}$.

A análise estatística foi efetuada segundo a análise da variância (ANOVA) para comparação entre as médias obtidas nos diferentes grupos. Quando havia diferença, utilizou-se o teste de Tukey para distinguir quais grupos diferiam entre si. Para comparar frequiências (taxa de mortalidade) usou-se o teste do qui-quadrado $\left(\chi^{2}\right)$. Em qualquer situação, adotou-se o nível crítico de $5 \%(\mathrm{p}<0,05)$.

\section{RESULTADOS}

O experimento contou com um total de 75 animais, dos quais, em virtude da mortalidade espontânea, restaram 53 camundongos para o sacrifício. A taxa de mortalidade determinada pela infecção foi superior à causada pela desnutrição $(47,4 \%$ versus $12,5 \% ; \mathrm{p}<0,05)$. Os grupos submetidos à dieta multideficiente apresentaram um padrão de crescimento inferior ao daqueles alimentados com a dieta controle $(\mathrm{p}<0,0001)$. Também animais infectados, mesmo alimentados com a dieta controle, desenvolveram-se ponderalmente menos que aqueles não infectados $(\mathrm{p}<0,009)$.

Os indicadores bioquímicos apresentaram alterações que estão designadas na Tabela 1.

Tabela 1 - Valores bioquímicos obtidos no soro de camundongos infectados ou não pelo Schistosoma mansoni, alimentados com dieta controle ou desnutridos pelo consumo da dieta básica regional.

\begin{tabular}{|c|c|c|c|c|c|}
\hline \multirow[b]{2}{*}{$\begin{array}{l}\text { Indicadores } \\
\text { bioquímicos }\end{array}$} & \multicolumn{2}{|c|}{ Dieta controle } & \multicolumn{2}{|c|}{ Dieta básica regional } & \multirow[b]{2}{*}{$\begin{array}{l}\text { p-valor } \\
\text { (ANOVA) }\end{array}$} \\
\hline & $\begin{array}{c}\text { sem } \\
\text { infecção }\end{array}$ & $\begin{array}{c}\text { com } \\
\text { infecção }\end{array}$ & $\begin{array}{c}\text { sem } \\
\text { infecção }\end{array}$ & $\begin{array}{c}\text { com } \\
\text { infecção }\end{array}$ & \\
\hline $\operatorname{ALT}(\mathrm{U} / \mathrm{L})$ & $60,9 \pm 10,98^{b}$ & $112,4 \pm 43,3^{\mathrm{a}}$ & $97,6 \pm 15,2^{\mathrm{ab}}$ & $83,1 \pm 16,45^{\mathrm{b}}$ & 0,002 \\
\hline $\operatorname{AST}(\mathrm{U} / \mathrm{L})$ & $111 \pm 15,72^{\mathrm{b}}$ & $237 \pm 32,26^{\mathrm{a}}$ & $128 \pm 20,99^{b}$ & $151 \pm 24,79^{b}$ & 0,0001 \\
\hline Fosfatase alcalina (U/L) & $158 \pm 19,42^{\mathrm{b}}$ & $232 \pm 21,06^{\mathrm{ab}}$ & $279 \pm 81,05^{\mathrm{a}}$ & $263 \pm 24,55^{\mathrm{ab}}$ & 0,001 \\
\hline Relação AST:ALT & $1,83 \pm 0,22^{\mathrm{ab}}$ & $2,12 \pm 0,77^{\mathrm{a}}$ & $1,32 \pm 0,19^{\mathrm{b}}$ & $1,84 \pm 0,17^{\mathrm{ab}}$ & 0,032 \\
\hline Glicemia (mg/dL) & $96,2 \pm 16,5^{a}$ & $35,2 \pm 22,85^{\mathrm{bc}}$ & $39,63 \pm 5,6^{b}$ & $13,57 \pm 4,77^{c}$ & 0,0001 \\
\hline Albumina $(\mathrm{g} / \mathrm{dL})$ & $2,56 \pm 0,25^{a}$ & $2,50 \pm 0,40^{\mathrm{ab}}$ & $2,04 \pm 0,25^{\mathrm{b}}$ & $2,02 \pm 0,15^{\mathrm{b}}$ & 0,02 \\
\hline Proteínas totais $(\mathrm{g} / \mathrm{dL})$ & $4,39 \pm 0,94^{\mathrm{ab}}$ & $5,50 \pm 1,24^{\mathrm{a}}$ & $3,49 \pm 0,39^{b}$ & $3,51 \pm 0,28^{b}$ & 0,005 \\
\hline ALB: GL & $1,71 \pm 0,21$ & $2,20 \pm 0,71$ & $1,86 \pm 0,78$ & $1,73 \pm 0,03$ & 0,35 \\
\hline
\end{tabular}

ALT: alanina aminotranferase, AST: aspartato aminotransferase, ALB: GL= relação albumina: globulina; valores expressos sob a forma de média \pm DP; médias para a mesma característica com a mesma letra não diferem entre si $(\mathrm{p}>0,05$; teste de Tukey). 


\section{DISCUSSÃo}

Neste estudo, todos os grupos, comparados ao controle, apresentaram elevação da ALT, fato que evidencia a alteração funcional do fígado causada pela desnutrição e/ou esquistossomose. Os índices dos animais do grupo controle infectado foram mais elevados, o que indicaria um processo inflamatório mais intenso, esperado nos animais normonutridos 9 . Com relação à AST, o grupo controle infectado também apresentou os níveis mais altos que os outros grupos, possivelmente pelas mesmas causas. Nesse mesmo grupo, os valores de AST ultrapassaram em dobro os de ALT, o que poderia exprimir uma maior gravidade e profundidade da lesão. A elevação simultânea de AST e de FA no grupo controle infectado leva à suposição de que o processo de colestase, causado pela tensão contínua e compressão focal nos ductos ${ }^{5}$, foi mais acentuado nele. A relação AST: ALT foi semelhante entre os grupos deste estudo. Em humanos ${ }^{22}$, uma razão maior que 1 é critério para diagnóstico de severo comprometimento hepático. Nesta pesquisa com camundongos, a razão ultrapassou esse índice em todos grupos, mas houve semelhança com o grupo controle.

Níveis altos de FA, como aqui observados, mesmo no controle normal, tem sido encontrados nos resultados do Centro de Bioterismo da Faculdade de Medicina de São Paulo ${ }^{21}$, e as causas estão sendo pesquisadas. Também em uma pesquisa com humanos, portadores ou não de esquistossomose ${ }^{6}$, foram observados níveis altos da FA, inclusive no grupo controle, sem infecção.

Neste estudo, nos animais do grupo controle infectado, foi a esquistossomose que pareceu causar elevação nos níveis da AST e da FA, o que é uma forte indicação de colestase.

A concentração sérica das aminotransferases informa o grau da lesão no hepatócito, uma vez que sua liberação no soro pode significar morte celular. A concentração sérica de ALT é melhor indicador para avaliação da integridade celular do fígado que a de $\mathrm{AST}^{4}$. A alteração de FA relaciona-se diretamente à obstrução biliar de causas intra e extra hepáticas, e/ou à lesão hepatocelular ${ }^{17}$, por isso é o indicador mais usado para o diagnóstico de colestases.

Sabe-se que a desnutrição causa deterioração das funções hepáticas, com alterações sorológicas relativas à ALT, AST e $\mathrm{FA}^{19}$. Na esquistossomose, a alta carga parasitária seria um dos mecanismos de elevação de ALT $^{12}$ e a inflamação decorrente afetaria os níveis das enzimas hepáticas ${ }^{20}$. Todavia os efeitos da infecção pelo Schistosoma mansoni sobre o desempenho do fígado são ainda controversos ${ }^{1120}$, as alterações da função hepática na esquistossomose parecem depender, não só do grau de fibrose, mas da intercorrência de outras infecções.

A hipoalbuminemia ocorreu apenas em função da desnutrição, uma vez que a infecção não alterou a função hepática, com referência à síntese protéica. Por outro lado, a esquistossomose promoveu um aumento na síntese de proteínas totais, provavelmente de globulinas. No entanto, foi o estado nutricional que repercutiu na proteinemia sérica ${ }^{19}$.

Entre os grupos estudados no presente experimento, apenas o grupo controle não apresentou hipoglicemia. Nos animais desnutridos, parece óbvio que um dos fatores relacionados a esse fato diz respeito à pequena reserva de glicogênio hepático disponível para manutenção da glicemia nos momentos pósprandiais ou de jejum ${ }^{18}$, situação em que se procedeu a coleta de sangue dos animais. Por outro lado, a hipoglicemia verificada nos animais do grupo controle infectado poderia indicar inabilidade hepática para conduzir a gliconeogênese, já que o fígado (e os rins em menor proporção) é o principal órgão que produz glicose a partir de outros substratos que não carboidratos.

Neste estudo aqui, os animais controle com infecção apresentaram hipoglicemia com valores próximos dos desnutridos sem infecção, o que revelou uma repercussão semelhante da infecção ou da desnutrição sobre os níveis da glicose plasmática. Ambas, desnutriçãa ${ }^{18}$ e infecção ${ }^{2}$ causam depressão nos níveis da glicemia. Resultados muito baixos foram encontrados nos animais desnutridos e infectados, provavelmente pelo sinergismo entre desnutrição e infecção.

Alguns dos trabalhos já mencionados acima reiteram que as alterações da função hepática se manifestariam proporcionalmente à gravidade da infecção esquistossomótica ou da desnutrição. Neste estudo, observou-se que desnutrição e/ou infecção podem interferir nos níveis esperados dos indicadores hepáticos, porém, as alterações da função hepática foram mais importantes quando o processo inflamatório da esquistossomose mostrou-se mais intenso ${ }^{9}$, levando ao aumento das aminotransferases.

\section{AGRADECIMENTO}

À Professora Eridan Coutinho, Centro de Pesquisa Aggeu Magalhães da Fundação Oswaldo Cruz (PE), pelo fornecimento de animais para 0 experimento.

\section{REFERÊNCIAS}

1. Abou-Basha LM, Salem A, Osman M, El-Hefni S, Zaki A. Hepatic fibrosis due to fascioliasis and/or schistosmiasis in Abia 1 village, Egypt. Eastern Mediterranean Health Journal 6: 870-878, 2000.

2. Ahmed SA, Gad MZ. Effect of schistosomal infection and its treatment on some key enzymes of glucose metabolism in mice livers. Arzneimittelforschung 45:1324-1328, 1995

3. Amaral ACC, Aguiar LAK, Souza MRA, Toledo CF, Borges DR. Elevação da $\Upsilon$ glutamiltransferase sérica na hepatopatia esquistossomótica não se correlaciona com a carga parasitária e precede alterações ultra-sonográficas. Arquivos de Gastroenterologia 39: 27-31, 2002.

4. Awadalla HN, Sherif AF, Shafei AZ, Khalil HA, Gurgis FK. Enzyme levels in homogenate of liver from mice infected with Schistosoma mansoni and from uninfected mice. International Journal of Parasitology 5: 27-31, 1975.

5. Barreto UST. Alkaline phosphatase in schistosomiasis. Annals of Internal Medicine 74: 450-451, 1971.

6. Camacho-Lobato L, Borges DR . Early liver dysfunction in schistosomiasis. Journal of Hepatology 29: 223-240, 1998.

7. Coutinho A. Fatores relacionados com o desenvolvimento das formas clínicas da esquistossomose mansônica. Revista da Associação Médica Brasileira 25: $185-188,1979$

8. Coutinho EM. Relações hospedeiro-parasito na esquistossomose mansônica em função da dieta básica regional: estudo anátomo-patológico. Tese Livre-Docência, Universidade Federal de Pernambuco, Recife, 1976. 
9. Coutinho EM. Malnutrition and hepatic fibrosis in murine schistosomiasis. Memórias do Instituto Oswaldo Cruz 99: 85-92, 2004.

10. El-Shazly AM, Soliman M, El-Kalla MR, Resk H, El-Nemr HE, Handousa AE, Helmy MM. Studies on patients with schistosomiasis mansoni, HCV and/or typhoid fever. Journal Egypt of Society of Parasitology 31: 583-592, 2001.

11. Fahim FA, Esmat AY, Hassan GK, Abdel-Bary A. Biochemical changes in patients with combined chronic schistosomiasis and viral hepatitis $\mathrm{C}$ infections. Disease Markers 16: 111-118, 2000.

12. França AVC, Carrilho FJ, Silva LC, Laudanna AA. Prováveis mecanismos de elevação da alanina aminotransferase na esquistossomose mansônica. Revista do Instituto de Medicina Tropical de São Paulo 35: 27-31, 1993.

13. Güler AH, Sapan N, Ediz B. Genc Z, Ozkan K. Effect of copper on liver and bone metabolism in malnutrition. The Turk Journal of Pediatrics 36: 205-213, 1994

14. Güler AH, Sapan N, Salantur E. Effects of cortisol and growth hormone on the metabolism of liver and bone in children with malnutrition. The Turk Journal of Pediatrics 34: 21-24, 1992.

15. Katz N, Chaves A, Pellegrino J. A simple device for quantitative stool thick smeal technique in shistosomiasis mansoni. Revista do Instituto de Medicina Tropical de São Paulo 14: 397-400, 1972.
16. Katz N, Peixoto SV. Análise crítica da estimativa do número de portadores de esquistossomose mansoni no Brasil. Revista da Sociedade Brasileira de Medicina Tropical 33: 303-308, 2000.

17. Lima AAAL, Ramalho LNZ, Zucoloto S, Bagnato VS, Silva Júnior OC. Estudo da fosfatase alcalina em ratos cirróticos hepatectomizados após aplicação de laser. Acta Cirurgica Brasileira 16: 16-17, 2001.

18. Okitolanda W, Brichard SM, Henquin JC. Repercussions of chronic protein-calorie malnutrition on glucose homeostasis in the rat. Diabetologia 30: 946-951, 1987.

19. Onyeneke EC, Njoya HK, Ebot MN, Uchungo GA, Eriyamremu GE, Alumanah EO. Liver function status in some nigerian children with protein energy malnutrition. Orient Journal of Medicine 15: 58-63, 2003.

20. Tao J, Peng HK, Cai WM, Dong FK, Weng HL, Liu RH. Influence factors of serum fibrosis markers in liver fibrosis. World Journal of Gastroenterology 9: 2497-2500, 2003.

21. Universidade de São Paulo. Faculdade de Medicina. Parâmetros biológicos dos animais de experimentação no Biotério da FMUSP. São Paulo. Disponível em: http://www.tcirurgica.fm.usp.br/bioterio/asnell/bioquimica.doc. Acesso em: 27/11/04, 2004.

22. Zaki A, Bassili A, Amin G, Aref T, Kandil M, Abou Basha LM. Morbidity of schistosomiasis in rural Alexandria, Egypt. Journal of the Egyptian Society of Parasitology 33: 669-710, 2003. 